\title{
Development and application of CatFACS: Are human cat adopters influenced by cat facial expressions?
}

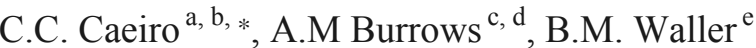 \\ a School of Psychology, University of Lincoln, Brayford Pool, Lincoln LN6 7TS, UK \\ b School of Life Sciences, University of Lincoln, Brayford Pool, Lincoln LN6 7TS, UK \\ ${ }^{c}$ Department of Physical Therapy, Duquesne University, Pittsburgh, PA, United States \\ ${ }^{\mathrm{d}}$ Department of Anthropology, University of Pittsburgh, Pittsburgh, PA, United States

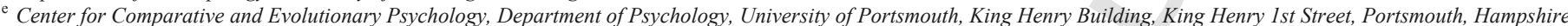 \\ PO1 2DY, UK
}

\section{A R T I C L E INFO}

\section{Article history:}

Received 13 June 2016

Received in revised form 4 January

2017

Accepted 8 January 2017

Available online xxx

Keywords:

Animal-human interactions

Domestication

Facial expressions

FACS

Rubbing

\section{A B S T R A C T}

The domestic cat (Felis silvestris catus) is quickly becoming the most popular animal companion in the world. The evolutionary processes that occur during domestication are known to have wide effects on the morphology, behaviour, cognition and communicative abilities of a species. Since facial expression is central to human communication, it is possible that cat facial expression has been subject to selection during domestication. Standardised measurement techniques to study cat facial expression are, however, currently lacking. Here, as a first step to enable cat facial expression to be studied in an anatomically based and objective way, CatFACS (Cat Facial Action Coding System) was developed. Fifteen individual facial movements (Action Units), six miscellaneous movements (Action Descriptors) and seven Ear Action Descriptors were identified in the domestic cat. CatFACS was then applied to investigate the impact of cat facial expression on human preferences in an adoption shelter setting. Rehoming speed from cat shelters was used as a proxy for human selective pressure. The behaviour of 106 cats ready for adoption in three different shelters was recorded during a standardised encounter with an experimenter. This experimental setup aimed to mimic the first encounter of a cat with a potential adopter, i.e. an unfamiliar human. Each video was coded for proximity to the experimenter, body movements, tail movements and face movements. Cat facial movements were not related to rehoming speed, suggesting that cat facial expression may not have undergone significant selection. In contrast, rubbing frequency was positively related to rehoming speed. The findings suggest that humans are more influenced by overt prosocial behaviours than subtle facial expression in domestic cats.

(C) 2016 Published by Elsevier Ltd.

\section{Introduction}

The domestic cat expressive and communicative behaviour may have been influenced by domestication, and thus specifically selected to function within the human-cat relationship. One way to test how humans are affected by the behaviour of domestic animals, is to see which individual humans select in preference tests. An ideal naturalistic and real-world preference test is for example, when people adopt cats from shelters. The cat shelter adoption process can therefore be interesting to scientists not only from a welfare perspective, but also as a proxy for human preference for certain cats over evolutionary time. Waller et al. (2013) used dogs rehoming rates to assess whether certain behaviours gave dogs a selective advantage in a shelter environment. The research team concluded that dogs displaying higher frequencies of a very subtle brow raise were preferred by future adopters, likely due to a paedomorphic effect.

\footnotetext{
* Corresponding author at: School of Psychology, University of Lincoln, Brayford Pool, Lincoln LN6 7TS, UK.
}

Email address: ccorreiacaeiro@lincoln.ac.uk (C.C. Caeiro)
Cats have associated with humans for around 10,000 years $(\mathrm{Hu}$ et al., 2014). During this time, they have been subject to some degree of evolutionary selection processes, both natural and artificial (Yamaguchi et al., 2004; Driscoll et al., 2009a,b; Faure and Kitchener, 2009; Montague et al., 2014), that have resulted in the domestic species known to us today. Domestication is known to influence the morphology, behaviour and cognitive abilities of a species (Price, 1984; Driscoll et al., 2009a; Montague et al., 2014), but in the case of the domestic cat, researchers are only just starting to understand these modifications. The ancestor to the domestic cat was solitary, nocturnal and intolerant to humans (African wildcat: Mills et al., 1984; Macdonald et al., 2000; Driscoll et al., 2007, 2009a,b) whereas the modern domestic cat seems to be facultatively social and highly integrated into the human home environment. However, the extent to which cats have undergone significant morphological, genetic, and behavioural change due to domestication is debated. For example, Montague et al. (2014) argue that cats' genomes indicate only a slight domestication effect due to their relatively short cohabitation time with humans and the lack of clear differences from wildcats (with a few exceptions, such as pigmentation or docility). Nonetheless, the 
domestic cat seems well adapted to human environments (Fitzgerald and Turner, 2000) and is quickly becoming the most popular domestic animal in some countries (Serpell, 2000; Euromonitor, 2015).

Some studies on the perception of cat vocalisations suggest that some calls may have evolved specifically for human directed communication. Domestic cats are more vocal when compared to other carnivores (Peters and Wozencraft, 1989; Yeon et al., 2011), and their meows are mostly directed at humans and only infrequently produced for conspecifics (Bradshaw and Cameron-Beaumont, 2000; Yeon et al., 2011). Humans are able to accurately classify meow sounds (Nicastro and Owren, 2003) and attribute meaning and emotional context to these calls (Nicastro, 2002; Belin et al., 2008). McComb et al. (2009) proposed that specific types of purrs (with embedded meow sounds) exploit human sensory biases by mimicking human infant cries in order to solicit enhanced levels of attention and care. Thus, the origin of these vocalisations may be a process of neotenisation, as calls mostly produced in kittens (both wild and domestic species) have been retained in the adult domestic cat during domestication (Cameron-Beaumont, 1997; Nicastro, 2004; Yeon et al., 2011; Bradshaw, 2016). It was also shown that domestic cat meows are more pleasant to the human ear than wild cat calls (Cameron-Beaumont, 1997; Nicastro, 2004), which supports the idea that human senses have been exploited during the evolution of the domestic cat vocal signals (Bradshaw and Cameron-Beaumont, 2000).

In comparison to acoustic behaviours, much less attention has been paid to the visual communicative repertoire of the domestic cat. Some behaviours do, however, appear to have been influenced by human domestication to some extent. For example, cats exhibit a tail up signal which seems to function as a greeting and affiliative behaviour when interacting with both conspecifics and humans (Dards, 1983; Cameron-Beaumont, 1997; Cafazzo and Natoli, 2009). This behaviour is often accompanied by head and/or flank rubbing and sniffing, but again this behaviour is not restricted to interactions with humans (Cameron-Beaumont, 1997; Mertens and Turner, 1988). Persistent close proximity or initiation of approach (with an affiliative outcome) also seems to be part of the positive social repertoire of the domestic cat to both conspecifics and humans (Mertens and Turner, 1988; Barry and Crowell-Davis, 1999; Wolfe, 2001; Curtis et al., 2003; Siegford et al., 2003).

Regarding cat facial expressions, there are some data suggesting that these behaviours can be meaningful in cats. There is evidence of pain facial indicators in clinical settings (Holden et al., 2014; Merola and Mills, 2016) and Gaynor and Muir (2008) report that behavioural indicators such as "squint eyes", or "abnormal facial expression" are used to clinically determine a painful facial expression. Various anecdotes and emotional classification systems of cat facial expression have also been published (Darwin, 1872; Leyhausen and Tonkin, 1979; Dards, 1983; Gaynor and Muir, 2008) and specific facial movements are occasionally mentioned in popular science and veterinarian texts (e.g. "slow eye blink": Tabor, 1997; "small blinks": Gruart et al., 1995; and "cat kiss"). However, to date there is no evidence that any of these signals are adaptive in cats, or have any specific role within cat-human interaction. To examine domestic cat facial expression in detail, we need to use objective and standardised tools, such as the Facial Action Coding System (FACS: Ekman and Friesen, 1978; Ekman et al., 2002). This system has been widely used for humans (Cohn et al., 2007) and has been successfully adapted and applied with other species (e.g. Waller et al., 2012; Caeiro et al., 2013; Waller et al., 2013). FACS bases its coding of facial movements on the muscular activity instead of the traditional emotion labelling system, by assigning independent codes (Action Units) to each facial muscle contraction (Ekman et al., 2002; Cohn et al., 2007). By basing a coding system on the underlying musculature, the meaning and function of facial movements can be disentangled and examined separately. Additionally, due to the well conserved facial musculature across mammals (Huber, 1930; Burrows, 2008; Diogo et al., 2009), basing the coding system on muscle homologies allows appropriate cross-species comparisons. This identification of the facial movements also takes into account individual differences in facial morphology (e.g. variation in fatty deposits) by using common facial landmarks (e.g. lip corners) among individuals and by establishing the minimum criteria needed to code each Action Unit.

One way to test whether domestic animal behaviour is specifically functional in interactions with humans, is to test whether specific behaviours affect which individual humans select in preference tests. Waller et al. (2013) used rehoming speed from dog shelters to assess whether specific facial expressions gave dogs a selective advantage in attracting human investment (adoption). Dogs displaying higher frequencies of brow raises were preferred by future adopters. The authors suggest this is due to the brow raise enhancing the paedomorphic features of the dog face (e.g. Archer and Monton, 2011), which may have been preferred by humans during domestication. Thus, dogs may have been tolerated more in human environments if they appeared more juvenile. The cat shelter adoption process can therefore also be used as a proxy for human preference for cats over evolutionary time.

Several studies have looked at the subjective reasons that influence adopters to choose a particular shelter cat (e.g. Weiss et al., 2012), the factors that predict a successful retention post-adoption (e.g. Kidd et al., 1992; Neidhart and Boyd, 2002) or why are cats relinquished after an unsuccessful pet ownership (e.g. Salman et al., 1998; Sharkin and Ruff, 2011; Casey et al., 2009). Future adopters tend to state that their choice of cat is influenced mainly by behavioural/emotional traits, increased activity and playfulness (e.g. HSUS, 1995; Gourkow, 2001). However, data show that tendency to sit at the front of the pen (Wells and Hepper, 1992) or physical characteristics (such as coat colour or breed: Podberscek and Blackshaw, 1988; Lepper et al., 2002; Delgado et al., 2012; Brown and Morgan, 2015) are the traits that most influence adopters' actual, final decisions (Gourkow and Fraser, 2006). Fantuzzi et al. (2010) also found a positive relationship between activity levels, viewing time and adoption decision in shelter cats. Interestingly, owners do not usually report attending to subtle behaviours (e.g. HSUS, 1995; Gourkow, 2001), such as the cats' facial expressions.

The aim of the current study was to better understand the production of facial movements in the domestic cat and test whether these movements have been specifically honed for human-cat interaction. First, we developed CatFACS, a standardised, anatomical and unbiased tool to study facial communication in the domestic cat. Second, in the first application of CatFACS, we tested whether cat facial expression influences adoption decisions in a cat shelter environment.

\section{Material and methods}

\subsection{Study 1: development of CatFACS}

We followed the standard modification procedure of FACS (Ekman and Friesen, 1976) for use with other species (e.g. Vick et al., 2007; Waller et al., 2013). First, we examined the existing literature on the facial musculature of the domestic cat and performed a subsequent comparison with humans' facial musculature (Ekman et al., 2002; Diogo et al., 2009, 2012) to identify possible muscular homologies. Original dissections of the facial muscles have been carried out in some cases (e.g. Vick et al., 2007; Waller et al., 2013), but due to the extensive literature available on the facial musculature of the domestic cat (Mivart, 1881; Reighard and Jennings, 1901; Davidson, 
1927; Crouch, 1969; Done et al., 1996; Tomo et al., 2002), this was deemed unnecessary. Second, the form and location of muscles were matched to observed facial movements by analysing frame-by-frame spontaneous facial behaviour from video footage. Third, the facial movements observed in the videos were described using specific directional and anatomical terms (Ekman et al., 2002). Each of the cat facial movements was classified according to the same codes used for previous FACS with new codes added if new movements were identified, including Action Units (AU), Action Descriptors (ADs), and Ear Action Descriptors (EADs). In the AUs, the observed movement is linked to its underlying mimetic musculature innervated by the facial nerve (Burrows, 2008), ADs describe more broad movements produced by non-mimetic facial musculature, and EADs code the different movements produced by the ear musculature. Gross behaviours, general actions not based on a particular muscle, such as head turns or vocalisations, are also described.

As with all FACS systems, a process of inter-rater reliability followed by improvement and adaptation of the manual (Wexler, 1972; Ekman et al., 2002) was performed between the first author (CC) and an independent certified human FACS coder.

\subsubsection{Individuals and data collection}

A sample of seven hours of domestic cats' spontaneous behaviour, targeting the face of 126 individuals was selected opportunistically. Part of the footage was recorded by the owners or by the first author (CC) from privately-owned cats $(1 \mathrm{~h})$, while the rest of the videos were extracted from www.youtube.com (after permission granted from respective owners/users). This sample consisted of cats living in 13 different countries, included 30 females and 25 males (71 not identified) of varied breeds (including Bengal, Calico, Domestic Short Hair, Exotic Shorthair, LaPerm, Maine Coon, Norwegian Forest, Persian, Savannah, Siamese, Siberian, Singapura, and Sphinx), that ranged from two months to 19 years old. Since it is important in the development of a FACS system to try to capture the whole range of facial movements of a species, the videos were selected to feature a wide-range of contexts, such as conspecific and heterospecific play behaviour, feeding, agonistic and affiliative interactions, grooming, resting, among others. Having a very heterogeneous sample of cats in different contexts and environments, ensured the observation of the maximum potential of facial movements in the domestic cat as a species. Nonetheless, it is still possible that some movements are very infrequently produced or are restricted to very specific contexts (e.g. mating) and thus, not present in the footage here sampled. However, due to the dynamic nature of the CatFACS manual, it is possible to easily add new information to the current manual.

\subsubsection{The CatFACS manual}

The proposed movements of each facial muscle taken from the literature review were matched with frame-by-frame analyses of the videos collected. Each independent facial movement observed on the cat's face was described in terms of appearance changes, minimum criteria and was classified following FACS methodology (Table 1: full manual available from www.catfacs.com). All the movements are illustrated in the full CatFACS manual by several still images and short embedded video-clips that can be watched in order to learn to identify the movement. The aim of the manual is, not only to compile the full range of facial movements produced by the domestic cat, but also to train coders to identify these movements in a standardized way. In order to use the CatFACS, the coder must become certified, by taking the CatFACS test, which ensures reliability between all coders using the system.
Table 1

Code and designation of AUs, ADs, gross behaviours, and EADs included in the CatFACS, with the corresponding underlying muscular basis. For more information and visual examples, please see the CatFACS manual available on www.CatFACS.com.

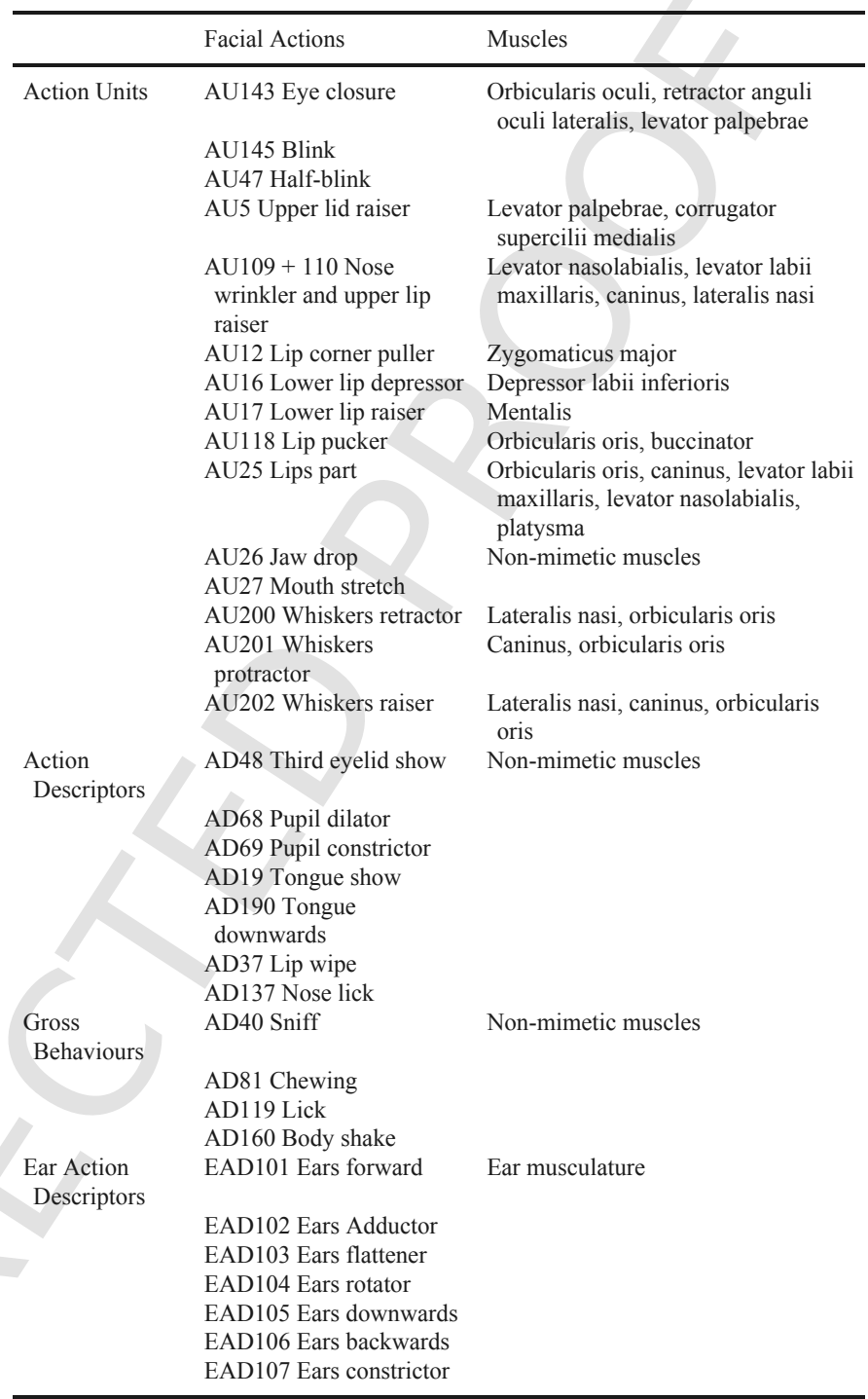

2.2. Study 2: application of the CatFACS in the adoption of shelter cats

After the development of the CatFACS, this tool was applied for the first time in a study exploring the cat-human communication when future adopters select a cat in a shelter. Study 2 also aimed to serve as a validation measure, demonstrating that the system can be used to code facial movements in a different set of cats, in a real-life context, and thus is a usable system (see 2.1.2).

\subsubsection{Individuals, housing and adoption process}

A total of 106 cats from three animal rescue centres in the United Kingdom, UK (Isle of Wight Cats Protection, IWCP and two branches of the Royal Society for the Prevention of Cruelty to Animals, RSPCA, in South Godstone and Southall) were filmed for this 
study. Only individuals ready to be adopted and habituated to the shelter were filmed, thus excluding individuals in the quarantine period (min 10 days) or yet without a veterinary check-up. From this sample, 59 cats were female, 47 were male, all neutered and ranging from 6 months to 14 years old.

All three centres had similar housing facilities, with consecutive rows of indoor pens with its flooring at approximately the height of a human waist. Each indoor pen had a transparent door, a bed, blankets, toys/enrichment objects and a water bowl. All pens connected through a catflap to another enclosure with more enrichment objects and outdoor visual access through mesh or metallic bars. In two of the shelters, some areas had another row of pens across the aisle where some of the individuals could see each other. Future adopters had visual, acoustic and olfactory access to the animals from either side of the pen (Fig. 1). Adopters could request to have physical interaction with each cat as well. The cats were mostly housed individually in their pens, except in cases where cats were to be adopted together or if they were surrendered from a home where they previously cohabited without agonistic interactions. Radio music was used as environmental enrichment in the shelters during opening hours. Staff cleaned the pens and fed the animals daily in the morning. Medical care and handling/playing by staff and volunteers were undertaken throughout the day. Next to the pens there was an individual information sheet with name, shelter ID number, sex, age, breed, neutering status, reason and date entering the shelter and a short description of the history and/or temperament of each cat.

In order to adopt a shelter cat in the UK, generally the same basic steps are followed in all adoption centres: (1) future adopter browses and selects a cat, (2) application form is filled out by future adopter, (3) if the application is approved, the staff will arrange a home check, (4) the cat can be taken home by the future adopter. While there might be slight differences in the steps order or between adoption centres, all future adopters have to go through most of these steps, including a minimum of one visit to the centre to meet the chosen cat. Additionally, there was an adoption fee (at the time of this study ranging from $£ 50$ to $£ 85$ depending on shelter and number of cats adopted). All three centres had a no-kill and a limited-admission policy, i.e. no healthy animals are put to sleep, but admission of new individuals is limited to the centre capacity. For further information on the adoption process of the shelters visited for this study, please consult their respective websites (www.cats.org.uk, www.rspca.org.uk).

\subsubsection{Data collection and video coding}

Each cat was filmed for $120 \mathrm{~s}$ (focal sampling) during an initial contact with the experimenter. This duration was chosen based on previous studies that reported that future adopters spent a maximum of $99 \mathrm{~s}$ (average of $70 \mathrm{~s}$ ) viewing each individual in a large shelter (Wells and Hepper, 2001). We increased this value to $120 \mathrm{~s}$ because the shelters visited for this study were smaller (maximum 40 individuals up for adoption) where visitors might spend longer looking at each cat. The videos were recorded in four sessions (IWCP was visited twice, but only newly-arrived cats were filmed on the second visit), between 11:30 $\mathrm{h}$ and 15:00 $\mathrm{h}$ and between October 2013 and March 2014. The experimenter used a handheld camcorder, model JVC GZ-MG750BEK at $25 \mathrm{fps}$, while standing in the middle front of each indoor pen and holding one hand by the pen door, at floor level, adjusting the hand position depending on the cat movement when near the door (Fig. 1). No cat was filmed while eating or being handled by the staff. Future adopters were not present in any of the data collection sessions, but normal routines of the shelter was still in place. The experimenter alternated the gaze between the camcorder screen and the individual being filmed and no other interactions took place between experimenter and subjects during filming. The gaze was alternated between the cat and the camera in order to mimic the gaze of a

A

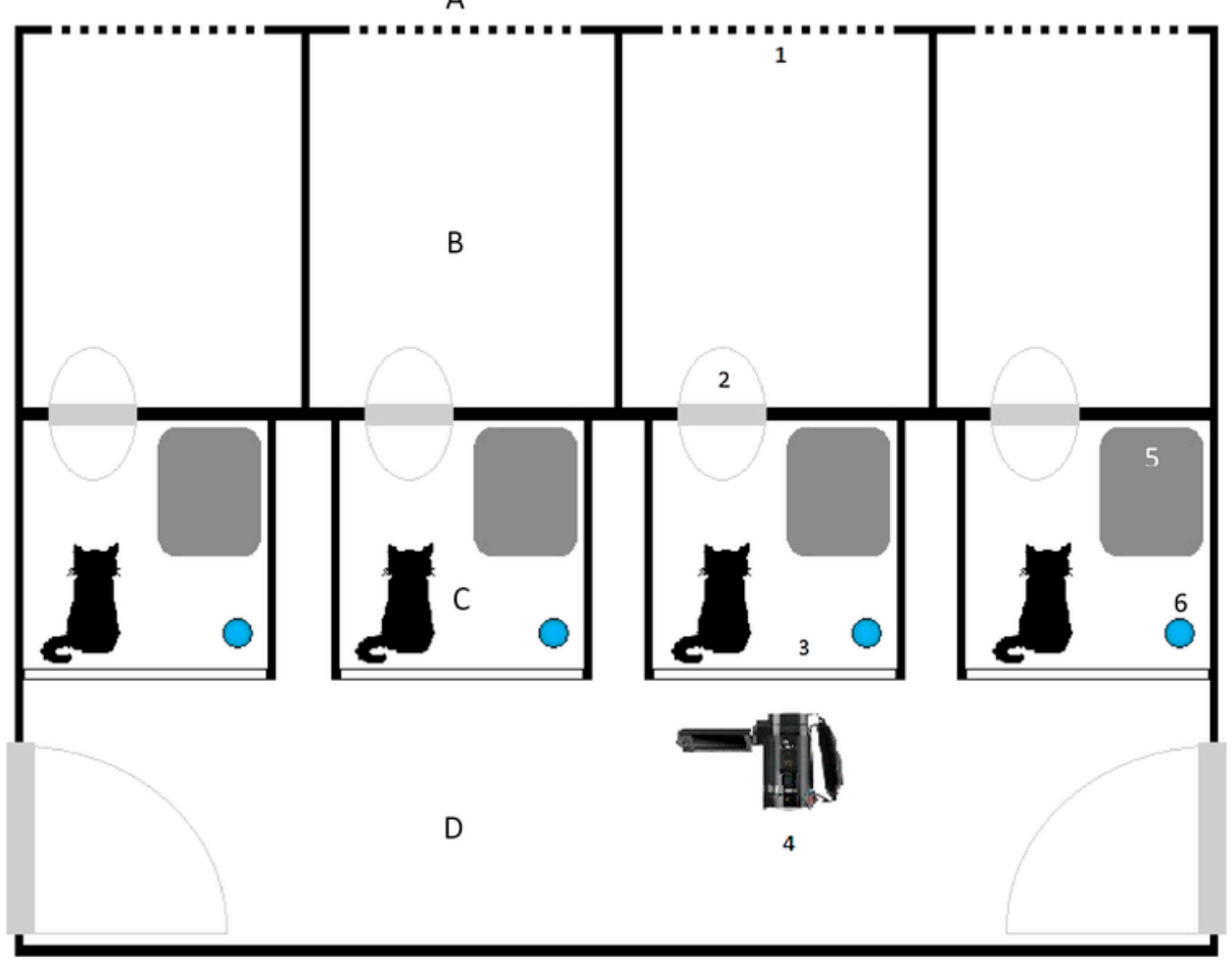

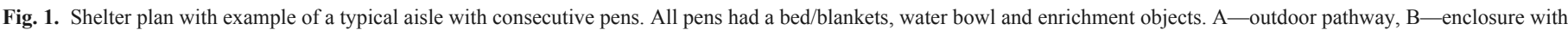
outside visual access, c-indoor pen, D-indoor aisle, 1-mesh/bars wall, 2-catflap, 3-pen door, 4-position of experimenter with camcorder, 5-bed, 6-water bowl. 
future adopter while at the same time ensuring the face and body of the cat was fully on camera, and to avoid staring which can be perceived as threatening by domestic cats (e.g. Dards, 1983; Kiddie, 2009).

The 2 min clips were coded for proximity and gaze focus time on the experimenter, body, tail and vocalisations (Table 2), totalling 26 variables. The facial movements were fully coded with CatFACS (33 variables, Table 1). The videos were analysed frame-by-frame using Adobe Premiere Pro CS4 v.4 and the Behavioural Variables (59 variables) were entered in Microsoft Office Excel 2007. Inter-reliability tests (ICC: Intra-class correlations) were conducted on all Behavioural Variables, between the author (CC) and independent coders (blind to the aim of the study) for five individuals ( $6 \%$ of the sample). The coders scored a mean of 0.869 , with a $95 \%$ CI range of $0.811-0.910$, $\operatorname{ICC}(3, \mathrm{k})$, for FACS behaviours; a mean of 0.887 , with a $95 \% \mathrm{CI}$ range of $0.826-0.927, \operatorname{ICC}(2, \mathrm{k})$, for behaviours coded as durations; and a mean of 0.993 , with a $95 \%$ CI range of $0.989-0.996$, $\operatorname{ICC}(2, \mathrm{k})$, for behaviours coded as events. No Behavioural Variables were removed from the analysis due to low inter-reliability agreement. These levels of inter-reliability agreement are very close to perfect agreement (Bartko, 1976).

Additionally, eight Non-Behavioural Variables were collected: shelter origin, reason for entering the shelter, number of cats housed in each pen, coat colour, eye colour, sex, breed and age (Table 3 ).

After the video analysis was completed, adoption dates were requested from the shelters and the number of days between becoming available for adoption and being rehomed was used as a dependent variable in all analyses (Length of Stay). Cats that were filmed but had not been rehomed by the time the data analysis was initiated (10 individuals), were deceased (three individuals) or were returned to owner (one individual) were not included in the analysis.

\subsection{Ethical statement}

All procedures described here were carried out in strict accordance with the recommendations in the ASAB/ABS guidelines for the use of animals in research and the study was approved by the University of Portsmouth Animal Ethics Committee.

\subsection{Statistical analysis}

Tail movement durations were transformed to percentages to account for non-visible periods. Initial exploratory analyses included a total of 67 variables (Behavioural and Non-Behavioural), but due to low production of the behaviour or high correlation between variables, 23 variables were removed (Table 4).

Since there were no initial assumptions about the data collected or the nature of the variables, an Exploratory Factor Analyses (EFA, e.g. Budaev, 2010; Williams et al., 2010) was performed with 36 Behavioural Variables in order to reduce data complexity, while retaining as much of the original relevant information as possible and avoiding multicollinearity (Cumming and Wooff, 2007). The number of factors to extract was calculated using parallel analysis (O'Connor, 2000), with raw data permutation and 1000 parallel datasets. With seven factors, several variables presented anti-image correlation matrix diagonal values below 0.5 or very low communalities $(<0.3)$. Further variable reduction followed by EFA was computed until all measures of sampling adequacy were satisfactory. The following 15 variables were thus removed: gaze focus on experimenter, tail down, stretch, AU5 (upper lid raiser), AU26 (jaw drop), AU143 (eye closure), AU201 (whiskers protractor), AU202 (whiskers raiser), AD19 (tongue show), AD119 (lick), AD40 (sniff), AD68 (pupil dilator), AD69
Table 2

Ethogram for all the behavioural variables (partly adapted from UK Cat Behaviour Working Group, 1995; Moelk, 1944; Bradshaw and Cameron-Beaumont, 2000).

\begin{tabular}{|c|c|}
\hline Behaviour & Description \\
\hline Approach door & $\begin{array}{l}\text { Time till individual walks to the door and places its head within } \\
\text { approximately } 5 \mathrm{~cm} \text { from the door, in front of the experimenter. } \\
\text { When a cat is already within this space, approaching time is } \\
\text { counted as zero, if upon visual inspection of experimenter the } \\
\text { individual does not walk away immediately }(1 \mathrm{~s}) \text {. }\end{array}$ \\
\hline $\begin{array}{l}\text { Proximity to } \\
\text { door }\end{array}$ & $\begin{array}{l}\text { Time individual spends at the front of the pen. An imaginary line } \\
\text { divided the pen in two halves, with the front half near the } \\
\text { experimenter/door and the back half near the catflap. }\end{array}$ \\
\hline $\begin{array}{l}\text { Gaze focus on } \\
\text { experimenter }\end{array}$ & $\begin{array}{l}\text { Time the individual spent looking at the experimenter face or } \\
\text { general upper body area. }\end{array}$ \\
\hline Tail up & $\begin{array}{l}\text { The tail is fully raised and maintained in a vertical position (with } \\
\text { or without vibration). }\end{array}$ \\
\hline Tail down & $\begin{array}{l}\text { The tail is hanging loose down, relaxed, without any other } \\
\text { movement other than the very subtle and slow movements } \\
\text { accompanying the body movement (for example, slight } \\
\text { oscillation while walking). }\end{array}$ \\
\hline Tail swish & The tail is moved from side to side with a quick movement. \\
\hline Tail flick & $\begin{array}{l}\text { The posterior portion of the tail (tip) is moved quickly and up and } \\
\text { down or form side to side. }\end{array}$ \\
\hline Lie & $\begin{array}{l}\text { Postural position where either the whole ventral side of the body } \\
\text { or the whole dorsal side of the body are touching the floor. }\end{array}$ \\
\hline Sit & $\begin{array}{l}\text { Postural position where the posterior part of the body is touching } \\
\text { the floor, hind legs are flexed next to the body and anterior legs } \\
\text { are straight in front of the body or partially straight. This } \\
\text { category includes crouching, as long as the anterior part of the } \\
\text { body does not touch the floor. }\end{array}$ \\
\hline Stand & $\begin{array}{l}\text { Postural position where the four paws are straight, mostly in } \\
\text { contact with the floor and no part of the body touches the floor. }\end{array}$ \\
\hline Walk & $\begin{array}{l}\text { Cat moves itself around, without any sudden or quick movements } \\
\text { and while maintaining alternated contact of the paws with the } \\
\text { floor. }\end{array}$ \\
\hline Hind legs & $\begin{array}{l}\text { Postural position where the individual stands up, raising the } \\
\text { anterior part of the body and anterior paws, while the posterior } \\
\text { paws stay on the floor. The anterior paws can be hanging up } \\
\text { without touching anything, or can be placed upon an object, } \\
\text { surface or another individual. }\end{array}$ \\
\hline Roll & $\begin{array}{l}\text { The individual lies on the floor and exposes the abdomen either } \\
\text { sideways or while lying on its back. }\end{array}$ \\
\hline Back arch & $\begin{array}{l}\text { The individual medial dorsal side is raised arching the back. The } \\
\text { four legs are straight. If there is any walking, this is done slowly } \\
\text { due to the position of the back. }\end{array}$ \\
\hline Lordosis & $\begin{array}{l}\text { The ventral side of the individual is pressed against the floor with } \\
\text { the posterior side of the body raised, usually exposing the } \\
\text { genitals. }\end{array}$ \\
\hline Meow & $\begin{array}{l}\text { The mouth opens and gradually closes in a slow movement while } \\
\text { a tonal sound is emitted with an arched pitch profile. }\end{array}$ \\
\hline Silent meow & $\begin{array}{l}\text { The mouth opens and closes in a slow movement, like in a normal } \\
\text { meow vocalisation, but no sound is emitted. }\end{array}$ \\
\hline Purr & $\begin{array}{l}\text { The individual produces a low-pitch rhythmical tone from its } \\
\text { chest and throat, produced during both exhalation and inhalation. } \\
\text { Usually, the mouth is closed and the body vibrates during the } \\
\text { sound production. }\end{array}$ \\
\hline Growl/hiss & $\begin{array}{l}\text { The individual produces sounds with the mouth held wide open. } \\
\text { Growl is a low pitch rumbling sound. Hiss is a drawn-out } \\
\text { "Shhhh" sound. }\end{array}$ \\
\hline Rub & $\begin{array}{l}\text { The individual rubs the face or body on the door of the pen. Rub } \\
\text { on objects or other parts of the pen other than the door were not } \\
\text { coded. }\end{array}$ \\
\hline Paw the door & $\begin{array}{l}\text { The individual places one or both front paws on the door of the } \\
\text { pen in a scratching movement. }\end{array}$ \\
\hline Knead & $\begin{array}{l}\text { Standing or lying down, the individual alternatively presses the } \\
\text { anterior paws on a surface (usually soft, e.g. blanket, other } \\
\text { individual) while extending the toes and nails wide and then } \\
\text { retracting them, in a repeated motion. }\end{array}$ \\
\hline
\end{tabular}


Table 2 (Continued)

\begin{tabular}{|c|c|}
\hline Behaviour & Description \\
\hline Yawn & $\begin{array}{l}\text { The mouth is slowly opened wide, the lips and lip corners are } \\
\text { retracted exposing usually all the frontal teeth, the tongue is } \\
\text { protruded and air is inhaled. It can be accompanied by a faint soft } \\
\text { sound. }\end{array}$ \\
\hline Flehmen & $\begin{array}{l}\text { The individual opens the mouth slightly, the lower jaw is lowered, } \\
\text { the head is held in a neutral position (or moved dorsally) and the } \\
\text { upper lip may be raised, holding this posture for a few seconds. }\end{array}$ \\
\hline Scratch & $\begin{array}{l}\text { The individual scratches or paws the floor, walls or other objects } \\
\text { inside the pen (except door). }\end{array}$ \\
\hline Stretch & The individual stretches the limbs in a slow movement. \\
\hline
\end{tabular}

Table 3

Non-Behavioural Variables of individuals entered in the analyses $(\mathrm{N}=87)$, with corresponding number of individuals and percentage per category. The Length of Stay mean and standard deviation is also given.

\begin{tabular}{|c|c|c|c|c|}
\hline NBV & $\mathrm{N}$ & $\%$ & LS means & LS SD \\
\hline \multicolumn{5}{|l|}{ Shelter origin } \\
\hline Isle of Wight Cats Protection & 37 & 42.5 & 58.19 & 5.85 \\
\hline Southall RSPCA & 32 & 36.8 & 61.25 & 6.95 \\
\hline South Godstone RSPCA & 18 & 20.7 & 56.39 & 9.18 \\
\hline \multicolumn{5}{|l|}{ Reason for entering shelter } \\
\hline Behavioural problems & 9 & 10.3 & 40.22 & 5.19 \\
\hline Welfare problems (confiscated) & 6 & 6.9 & 78.33 & 17.00 \\
\hline Owner moved house & 7 & 8 & 59.71 & 18.19 \\
\hline Owner death/taken into care/hospital & 11 & 12.6 & 59.09 & 7.84 \\
\hline Taken in as stray & 46 & 52.9 & 62.74 & 5.87 \\
\hline Other & 8 & 9.3 & 42.75 & 12.59 \\
\hline \multicolumn{5}{|l|}{ Number of cats per pen } \\
\hline One & 64 & 73.6 & 56.23 & 4.62 \\
\hline Two & 19 & 21.8 & 66.79 & 8.96 \\
\hline Three & 4 & 4.6 & 69.75 & 19.26 \\
\hline \multicolumn{5}{|l|}{ Coat colour } \\
\hline All black & 20 & 23 & 62.45 & 9.08 \\
\hline All white & 2 & 2.3 & 45.50 & 20.50 \\
\hline Black and white & 22 & 25.3 & 56.68 & 8.00 \\
\hline White and grey & 2 & 2.3 & 53.50 & 33.50 \\
\hline Tortoiseshell & 5 & 5.7 & 90.80 & 24.40 \\
\hline Light tricolour & 2 & 2.3 & 34.50 & 6.50 \\
\hline Dark tricolour & 6 & 6.9 & 74.67 & 22.66 \\
\hline Ginger & 7 & 8 & 50.00 & 12.06 \\
\hline Tabby & 19 & 21.8 & 51.47 & 5.41 \\
\hline Other & 2 & 2.3 & 67.50 & 30.50 \\
\hline \multicolumn{5}{|l|}{ Eye colour } \\
\hline Green & 17 & 19.5 & 60.53 & 6.99 \\
\hline Light green & 42 & 48.3 & 51.40 & 5.53 \\
\hline Yellow & 25 & 28.7 & 70.28 & 8.71 \\
\hline Blue & 2 & 2.3 & 61.50 & 36.50 \\
\hline Not identified & 1 & 1.2 & - & $->$ \\
\hline \multicolumn{5}{|l|}{ Sex } \\
\hline Female & 48 & 55.2 & 64.63 & 5.73 \\
\hline Male & 39 & 44.8 & 51.95 & 5.33 \\
\hline \multicolumn{5}{|l|}{ Breed } \\
\hline Domestic shorthair & 81 & 93.1 & 59.74 & 4.15 \\
\hline Domestic longhair & 5 & 5.7 & 50.40 & 18.85 \\
\hline Persian mix & 1 & 1.1 & - & - \\
\hline \multicolumn{5}{|l|}{ Age } \\
\hline 6 months to $\leq 1$ year & 23 & 26.4 & 68.78 & 42.30 \\
\hline 1 year to $\leq 2$ years & 24 & 27.6 & 46.58 & 24.24 \\
\hline 2 years to $\leq 3$ years & 14 & 16.1 & 48.79 & 36.48 \\
\hline$>3$ years & 26 & 29.9 & 66.23 & 40.13 \\
\hline
\end{tabular}

(pupil constrictor), AD137 (nose lick) and EAD107 (ears constrictor).The final extraction of factors with optimal parameters, grouped 21 variables in five factors, with Varimax rotation and Kaiser Normalisation.

Spearman's correlations were ran between the 21 Behavioural Variables resulted from the EFA and the Length of Stay, and also between

\section{Table 4}

List of variables removed during initial exploratory analysis with the corresponding reason for removal. When the variables were highly correlated, the variable removed was the one less correlated with Length of Stay. If the correlation coefficient was similar, the less conspicuous movement was removed. E.g.: lip corner puller (AU12) was highly correlated with mouth stretch (AU27). Since the mouth corners movements in cats are not easily visible, AU27, which stretches open the mouth and is highly conspicuous visually, was retained over AU12.

\begin{tabular}{|c|c|c|}
\hline Reason for removal & Variable & Descriptive for removal \\
\hline \multirow{17}{*}{$\begin{array}{l}\text { Low frequency/duration, i.e., } \\
\text { displayed by less than } 15 \% \text { of } \\
\text { individuals and produced less } \\
\text { than } 1 \text { time or for less than } 5 \mathrm{~s} \\
\text { in average }\end{array}$} & Lordosis & $\mathrm{N}=1$, average $=0.02$ \\
\hline & Purr & $\mathrm{N}=1$, average $=0.03$ \\
\hline & Growl/hiss & $\mathrm{N}=0$ \\
\hline & Flehmen & $\mathrm{N}=1$, average $=0.01$ \\
\hline & Scratch & $\mathrm{N}=2$, average $=0.02$ \\
\hline & Tail flick & $\mathrm{N}=3$, average $=0.056 \%$ \\
\hline & Tail swish & $\mathrm{N}=6$, average $=0.928 \%$ \\
\hline & Roll & $\mathrm{N}=5$, average $=1.3 \mathrm{~s}$ \\
\hline & Knead & $\mathrm{N}=6$, average $=0.08$ \\
\hline & Silent meow & $\mathrm{N}=10$, average $=0.34$ \\
\hline & Yawn & $\mathrm{N}=13$, average $=0.2$ \\
\hline & $\begin{array}{l}\text { AU17-lower lip } \\
\text { raiser }\end{array}$ & $\mathrm{N}=3$, average $=0.03$ \\
\hline & $\begin{array}{l}\text { AU118 - lip } \\
\text { pucker }\end{array}$ & $\mathrm{N}=2$, average $=0.02$ \\
\hline & AD37-lip wipe & $\mathrm{N}=10$, average $=0.6$ \\
\hline & $\begin{array}{l}\text { AD48 - third } \\
\text { eyelid show }\end{array}$ & $\mathrm{N}=1$, average $=0.01$ \\
\hline & $\begin{array}{l}\text { AD190 - tongue } \\
\text { downwards }\end{array}$ & $\mathrm{N}=1$, average $=0.01$ \\
\hline & AD81- chewing & $\mathrm{N}=2$, average $=0.02$ \\
\hline \multirow[t]{6}{*}{$\begin{array}{l}\text { High correlation (Spearman's } \\
\text { Rho }>0.8 \text { ) }\end{array}$} & Lie & $\begin{array}{l}\text { vs Approach door, } \mathrm{r}=0.8 \text {, } \\
\mathrm{P}<0.0001\end{array}$ \\
\hline & Stand & vs Walk, $\mathrm{r}=0.81, \mathrm{P}<0.0001$ \\
\hline & Walk & $\begin{array}{l}\text { vs Tail up, } \mathrm{r}=0.83 \\
\mathrm{P}<0.0001\end{array}$ \\
\hline & Back arch & $\begin{array}{l}\text { vs Tail up, } r=0.86 \\
\mathrm{P}<0.0001 \text {; vs Length of } \\
\text { Stay, } \mathrm{r}=-0.04, \mathrm{P}=0.69 \\
\text { Tail up vs Length of Stay, } \\
\mathrm{r}=-0.05, \mathrm{P}=0.63\end{array}$ \\
\hline & AU25-lips part & $\begin{array}{l}\text { vs AU26-jaw drop, } r=0.95 \\
P<0.0001\end{array}$ \\
\hline & $\begin{array}{l}\text { AU12-lip } \\
\text { corner puller }\end{array}$ & $\begin{array}{l}\text { vs AU27—mouth stretch, } \\
\mathrm{r}=0.81, \mathrm{P}<0.0001\end{array}$ \\
\hline
\end{tabular}

the EFA Factor Scores (Anderson-Rubin estimation method) and the Length of Stay, to look for meaningful relationships between variables. Whenever a significant result was found through the correlation analyses, power and linear curves regressions were fitted to the variable, in order to have a better understanding of how the variable was influencing the Length of Stay. For the regression curves, variables were $\log _{10}(x+2)$ transformed to eliminate zero values. In addition, post-hoc regression analyses were performed individually for all 21 Behavioural Variables. The normality and independence of residuals was inspected visually with histograms and errors plots. By increasing the type I error probability, this post-hoc analysis ensures the absence of underlying effects of any Behavioural Variables undetected through correlational analyses.

For the Non-Behavioural Variables, multiple regressions with stepwise method were performed, with Length of Stay as the dependent variable. Variables with more than two levels were dummy coded to be entered in the same regression model. Again, individual post-hoc ANOVAS were performed for each Non-Behavioural Variables, for 
the same reason stated above for the Behavioural Variables post-hoc analyses.

Interactions between Behavioural Variables and Non-Behavioural Variables were also explored in detail with Spearman's correlations and multiple regressions models. The variables were centred to avoid correlation with the interaction terms.

All statistical analyses were performed with IBM SPSS Statistics v.22 software.

\section{Results}

\subsection{Study 1: development of the CatFACS}

\subsubsection{The CatFACS manual}

In the CatFACS manual, 15 Action Units, seven Action Descriptors and seven Ear Action Descriptors were found (Table 1). The final agreement score for CatFACS was 84\% (Wexler, 1972; Ekman et al., 2002). Using the human FACS as a basis for the development of CatFACS, the identification and adaptation of each AU is commented below, accounting for major differences in musculature, morphology and other anatomical structures.

\subsubsection{AU143-eye closure and AU145 - blink}

In humans, AU43 (eyelids close for more than half a second) and AU45 (eyelids close for half a second or less) describe the closure of the eye, caused by the relaxation of levator palpebrae, which lowers the upper eyelid. This means that the eyes are kept opened by the sustained contraction of this muscle. Cats' eyelids differ in appearance from the ones in humans, as there is no prominent superciliary arch and consequently, no epicanthal fold. Since the eye area is anatomically and morphologically different in cats and humans, eye closure and blink movements have very different appearance changes in these species. In cats, the complete eye closure and blink do not appear to be due to the levator palpebrae muscle relaxation exclusively, as the appearance changes indicate contraction around the eye and recruitment of the lower eyelid. The lower eyelid is raised by contraction of the orbicularis oculi muscle and frequently compressed against the upper eyelid to completely shut the eye, which produces similar visual cues from the cheek raiser in humans (AU6, which pulls the skin towards the eye). So, it is proposed that the contraction of the orbicularis oculi is mostly responsible for eye closure and blink in cats, and that both eyelids (upper and lower) are involved in closing the eye completely. To account for all these differences in the muscular basis of cats, eye closure is coded as 143 and blink is coded as 145 .

\subsubsection{AU47-half-blink}

Cats display an eyelid movement pattern where the eyelids slowly move towards each other over the eyeball, without closing the eye, in a sequential manner. It can occur in a succession of movements (usually slow) or one movement only (slow or fast). Though not contextually tested, these movements have been described before under different names ("slow eye blink": Tabor, 1997; "small blinks": Gruart et al., 1995). This pattern of movements has not been observed in humans, so there is no corresponding $\mathrm{AU}$ code. To describe this sequence of movement unique in cats, the new code 47 was used.

\subsubsection{AU5-upper lid raiser}

This AU is produced in humans by the contraction of the levator palpebrae, which is also present in the domestic cat. Cats have another muscle attached to the upper eyelid, the corrugator supercilli medialis, which is not present in humans and that might be equally in- volved in producing an AU5 by dorsally pulling the upper eyelid and widening the eye aperture.

\subsubsection{AU109+110-nose wrinkler and upper lip raiser}

In humans, AU9 and AU10 are coded independently based on their distinctive appearance changes. In AU9, the levator labii superioris alaeque nasi muscle wrinkles the nose and in AU10, the levator labii superioris muscle raises the upper lip. In cats, due to the cranial prognathism and the slightly different relative position of the muscles, there is an overlap in the appearance changes of each AU, making it difficult to identify them independently. Additionally, cats have four muscles able to wrinkle the nose and/or raise the upper lip: levator nasiolabialis, levator labii maxillaris, caninus and lateralis nasi. Thus, in cats AU109 + AU110 are coded together.

\subsubsection{AU12 - lip corner puller}

The same muscle is producing this movement in cats and humans (Table 1), by pulling the lip corners towards the ears. In cats, the mouth corner is not readily visible in frontal or profile view, due to prognathism, skin folds and/or hair hiding the lip corner. Thus, lip corner movements may be difficult to detect and careful comparison with a neutral mouth area should be done before coding this AU.

\subsubsection{AU17-lower lip raiser}

In humans, the mentalis muscle located on the chin pushes the chin and the lower lip upwards and AU17 - chin raiser, is coded. Crouch (1969) mentions a transversus menti muscle that "stiffens the lower lip" in cats. This muscle is represented originating from the lower lip, bellow the canine tooth and inserting into the edge of the mental region, anatomically similar to the human mentalis muscle, by which the AU17 code was maintained for cats. However, cats do not possess a chin, which is an anatomical feature unique to the human face (Schwartz and Tattersall, 2000). Thus, this AU designation was modified to lower lip raiser, in order to describe the movement more accurately. In cats, AU17 codes a dorsal movement of the mental region that raises the lower lip.

\subsubsection{AU118-lip pucker}

In humans, this movement is caused by the action of the incisivii labii muscles. It is described by the puckering of the lips medially, de-elongating the mouth and tightening the lips, creating characteristic wrinkles (AU18 - lip pucker). In cats, the muscles are absent and the consequent movement of pushing the lips towards the midline has very different appearance changes. The buccinator muscle has been described as responsible for pushing the lips medially and keeping food inside the mouth, during mastication (Tomo et al., 2002). Since no puckering of the lips is seen in cats and there are different muscles acting, this movement is coded in cats as AU118 and the same designation is maintained. AU118 is coded when the lip corners are pushed cranially towards the mouth midline.

\subsubsection{AU200-whiskers retractor, AU201-whiskers protractor and} AU202-whiskers raiser

The whiskers in cats show independent movement from the upper lip. These movements can be observed in a dorsal plane, retracting caudally against the face - whiskers retractor (AU200) or being projected cranially and distally towards the face midline - whiskers protractor (AU201; Bradshaw et al., 2012). A third movement consisted on the whiskers being raised in a transversal plane - whiskers raiser (AU202). Several extrinsic muscles are described as being involved in the movement of the whiskers: lateralis nasi, the caninus and levator labii maxillaris, all which have origin or attachment at the whiskers 
pad. The orbicularis oris muscle may play a role in the movement of the whiskers as well (Ahl, 1986). Each individual whisker also has an intrinsic muscle band attached to its follicle, usually present in nocturnal animals that use whiskers for spatial recognition and navigating the environment (Muchlinski et al., 2013).

AU16-lower lip depressor, AU25-lips part, AU26-jaw drop and AU27 mouth stretch were directly taken from the human FACS without any major adaptations, as the muscular basis, the appearance changes and the minimum criteria to code are very similar, and thus they are not commented on here.

\subsection{Study 2: application of the CatFACS in the adoption of shelter cats}

\subsubsection{Exploratory data analysis}

Four individuals were excluded as outliers for the Length of Stay, based on a 1.5 IQR factor, by what 87 individuals were entered in all subsequent analysis (Table 3 ).

The dependent variable Length of Stay (mean $\pm \mathrm{SD}=58.94 \pm 37.30$ ) was not normally distributed $\left(\mathrm{W}_{87}=0.88, \mathrm{P}<0.0001\right)$, presenting positive skew (1.13), with a minimum of 11 days and a maximum of 167 days. These numbers indicate that Length of Stay was shorter for more individuals in this sample, with more than half $(64.4 \%)$ of the individuals being rehomed within two months (60 days) and only $20.7 \%$ staying for 3 months (90 days) or longer.

\subsubsection{Exploratory factor analysis}

The five factors extracted in the final EFA explained approximately $75 \%$ of variance and had a KMO of 0.783 . Loadings above 0.40 were retained in the final solution. This analysis allowed the grouping of Behavioural Variables according to its prevalence, revealing an underlying context or function interpretation with explainable factors (Table 5). All the Behavioural Variables loaded strongly $(>0.40)$ into only one factor, except for the rub behaviour that loaded into Factor 2 and Factor 5 with very similar values $(0.547$ and 0.524 , respectively) and ears rotator (EAD104) that loaded into Factor 3 (0.636) and Factor 4 (0.427), but stronger on Factor 3. In Factor 1, four facial movements, nose wrinkler and upper lip raiser (AU109+110), lower lip depressor (AU16), mouth stretch (AU27) and ears downward (EAD105) were grouped together with meow vocalisations, showing that whenever an individual meows these specific movements were displayed as well. Upper lip raisers, lower lip depressors and mouth stretches are facial movements related to the opening and enlarging of the oral aperture. The ear downwards movement which pulls the ears downwards is not known to be related to vocalisations, but in this study appears to be often displayed simultaneously. Factor 2 grouped seven Behavioural Variables that can be considered pro-social behaviours, including greeting and affiliative variables, where the individual is either emitting a positive signal towards the experimenter (e.g. tail up, Cafazzo and Natoli, 2009) or is acting as to overcome the door barrier and possibly establish physical contact with the experimenter (e.g. paw or rub on the door). The rub behaviour seems to be displayed along, not only with greeting behaviours (Factor 2 ), but also with eyelid movements (Factor 5). Factor 4 grouped approaching behaviours together, where cats that are faster to approach, sit for longer and stay longer at the front of the pen, near the experimenter. Since the ears rotator (EAD104) loaded significantly in Factor 4 as well, it can be assumed that the Ears rotator movement is displayed with approaching behaviours, though its value was marginally accepted and so it seems that is more frequently displayed with other ear movements. Factor 3 grouped together all the ear movements and Factor 5 grouped the eyelid movements.

\subsubsection{Relationship between behavioural variables and length of stay}

Spearman's Rho correlations indicated that the frequency of rubs was the only behaviour significantly correlated with Length of Stay $(r=-0.24, P=0.03)$, with the Length of Stay decreasing with the increase of number of rubs (Table 6). Linear and power curve regression models were a good fit for the data, with the power model $\left(\mathrm{F}_{1,85}=5.3\right.$, $\mathrm{P}=0.02)$ slightly better than the linear model $\left(\mathrm{F}_{1,85}=4.8, \mathrm{P}=0.03\right)$.

The post-hoc individual regressions for each Behavioural Variables and Length of Stay as dependent variable did not point out any significant effects, confirming the previous result where none of the Behavioural Variables affected the Length of Stay significantly (Supplementary Table 1). Importantly, the regression model including the rub variable was not significant, which could either be due to the analysis being more robust or a sign of other interactions between variables, which are explored in section 3.2.5.

Table 5

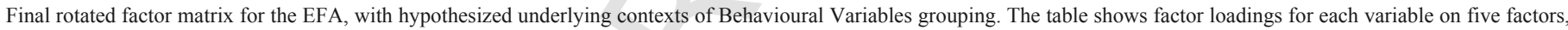
sorted by size. Loadings above 0.40 were retained in the final solution and are shown in bold. Communalities are also presented for each variable.

\begin{tabular}{|c|c|c|c|c|c|c|c|}
\hline Behavioural Variables & Factor 1 & Factor 2 & Factor 3 & Factor 4 & Factor 5 & Communalities & Contextualization \\
\hline AU109 + 110 Nose wrinkler and upper lip raiser & 0.924 & 0.024 & 0.111 & 0.102 & 0.032 & 0.877 & Meows and facial movements \\
\hline AU16 Lower lip depressor & 0.903 & -0.029 & 0.006 & 0.123 & 0.105 & 0.842 & \\
\hline Meow & 0.891 & 0.118 & -0.023 & 0.084 & -0.004 & 0.816 & \\
\hline AU27 Mouth stretch & 0.820 & 0.020 & 0.094 & 0.112 & -0.043 & 0.695 & \\
\hline EAD105 Ears downward & 0.695 & 0.284 & 0.365 & 0.278 & 0.086 & 0.782 & \\
\hline Hind legs & 0.134 & 0.955 & -0.042 & -0.007 & -0.127 & 0.948 & Pro-social behaviours: greeting and affiliative \\
\hline Paw the door & 0.124 & 0.806 & 0.198 & 0.049 & -0.009 & 0.707 & \\
\hline Tail up & -0.063 & 0.756 & 0.294 & 0.130 & 0.247 & 0.740 & \\
\hline EAD103 Ears flattener & 0.043 & 0.684 & 0.256 & 0.145 & 0.103 & 0.566 & \\
\hline Rub & -0.135 & 0.547 & 0.066 & 0.180 & 0.524 & 0.628 & \\
\hline AU200 Whiskers retractor & 0.089 & 0.520 & 0.255 & 0.248 & 0.262 & 0.474 & \\
\hline AD160 Body shake & 0.035 & 0.482 & 0.335 & 0.037 & 0.199 & 0.387 & \\
\hline EAD101 Ears forward & 0.098 & 0.088 & 0.743 & 0.058 & 0.048 & 0.575 & Ear movements \\
\hline EAD106 Ears backward & 0.124 & 0.265 & 0.740 & 0.174 & 0.113 & 0.677 & \\
\hline EAD102 Ears adductor & 0.042 & 0.211 & 0.738 & 0.181 & 0.025 & 0.624 & \\
\hline EAD104 Ears rotator & 0.086 & 0.389 & 0.636 & 0.427 & 0.127 & 0.762 & \\
\hline Approach door & -0.180 & -0.357 & -0.288 & -0.802 & -0.094 & 0.895 & Approaching \\
\hline Sit & 0.339 & -0.173 & 0.086 & 0.606 & -0.076 & 0.526 & \\
\hline Proximity to door & 0.119 & 0.229 & 0.198 & 0.594 & 0.079 & 0.464 & \\
\hline AU145 Blink & -0.021 & 0.100 & 0.082 & -0.077 & 0.855 & 0.754 & Blinks \\
\hline AU47 Half-blink & 0.368 & 0.069 & 0.110 & 0.155 & 0.500 & 0.426 & \\
\hline
\end{tabular}


Table 6

Spearman's correlations between Behavioural Variables selected in the Exploratory Factor Analysis and Length of Stay. Significant correlations indicated in bold.

\begin{tabular}{lll}
\hline Behavioural Variables & \multicolumn{2}{l}{ Length of Stay } \\
\hline & $\sigma$ & $P$ \\
\hline AU109 + 110 Nose wrinkler and upper lip raiser & 0.086 & 0.430 \\
AU16 Lower lip depressor & 0.100 & 0.360 \\
Meow & 0.052 & 0.629 \\
AU27 Mouth stretch & 0.161 & 0.138 \\
EAD105 Ears downward & -0.024 & 0.824 \\
Hind legs & -0.075 & 0.491 \\
Paw the door & -0.093 & 0.394 \\
Tail up & -0.033 & 0.760 \\
EAD103 Ears flattener & -0.044 & 0.690 \\
Rub & $-\mathbf{0 . 2 3 3}$ & $\mathbf{0 . 0 3 1}$ \\
AU200 Whiskers retractor & -0.075 & 0.501 \\
AD160 Body shake & -0.026 & 0.815 \\
EAD106 Ears backward & 0.106 & 0.330 \\
EAD101 Ears forward & 0.163 & 0.133 \\
EAD102 Ears adductor & -0.019 & 0.865 \\
EAD104 Ears rotator & 0.084 & 0.444 \\
Approach door & -0.044 & 0.689 \\
Sit & 0.086 & 0.427 \\
Proximity to door & 0.002 & 0.988 \\
AU145 Blink & 0.059 & 0.589 \\
AU47 Half-blink & 0.026 & 0.811 \\
\hline
\end{tabular}

Spearman's Rho correlations were also run between Length of Stay and Factor Scores from the EFA, with no significant results (Supplementary Table 2).

\subsubsection{Relationship between non-behavioural variables and length of stay}

Multiple regressions were performed with the Non-Behavioural Variables to see if any of the physical characteristics could be affecting the Length of Stay of cats in the shelter. Sex, coat colour "tortoiseshell" and reason "other" seemed to be significant when taken out of the model (i.e. they improved the model when included), but in post-hoc ANOVAS only sex was clearly significant $\left(\mathrm{F}_{1,86}=4.1\right.$, $\mathrm{P}=0.047$ ), with males having a shorter Length of Stay than females, even though they were less numerous overall (females: $\mathrm{N}=49$, mean $\pm \mathrm{SD}=67 \pm 42.67$ days; $\quad \mathrm{Nales}$ : $\quad \mathrm{N}=39$, mean $\pm \mathrm{SD}=51.95 \pm 33.25$ days $)$.

\subsubsection{Interactions between all variables and effects on length of stay}

Sequential interactions (two levels only to allow easier interpretation) were explored between all variables (Behavioural Variables and Non-Behavioural Variables), but only the multiple regression model including rub $\mathrm{x}$ sit interaction term was significant $\left(\mathrm{F}_{3,82}=3.6\right)$, $\mathrm{P}=0.02 . \mathrm{Rub}(\beta=-0.48, \mathrm{P}=0.01)$ and rub $\times$ sit $(\beta=-0.43, \mathrm{P}=0.02)$ where significant in the model, but the variable sit $(\beta=-0.05$, $\mathrm{P}=0.72$ ) alone was not significant. The overall fit of the model was $\mathrm{R}^{2}=0.085$. To understand how sitting time was interacting with the rub behaviour, the variable sit was grouped in three levels with the same number of individuals per level and regression equations were fit to the data (Fig. 2a). Cats that sit for a long time showed a higher correlation between number of rubs and Length of Stay, i.e. when cats sit for a long time, the rub behaviour is a stronger indicator of Length of Stay. Additionally, sit and proximity to door were highly correlated $(\mathrm{r}=0.46, \mathrm{P}<0.0001)$, i.e. cats that sat for longer periods would do it at the front of the pen (Fig. 2b).

\section{Discussion}

A wide range of movements was found during the development of the CatFACS as an anatomical and standardized tool to code facial movements in domestic cats. This might be surprising to some extent due to the species nocturnal and facultatively social nature, where facial expressions would be less useful as communicative signals, given that visual displays are usually dependent on clear and close-range access. These results also come to contradict the popular idea that domestic cats tend to be facially inexpressive (e.g. Bowden and Mahran, 1956). In fact, what was found here is that the basic muscle plan is quite similar to other carnivores, and the basic anatomical structure and function are not widely different when comparing with other taxonomical groups (e.g. Diogo et al., 2012). Additionally, the domestic cat has been found to have an extensive network of vibrissa with robust and well-developed intrinsic musculature (Muchlinski et al., 2013), which could influence the range of facial expressions as well. Thus, the domestic cat has the potential for complex and dynamic facial movements. More importantly, with the development of CatFACS, new questions can now be explored in cats that can focus on their interesting facial behaviour, and how and when the facial movements are being used in a wide range of contexts, as, for example, social and emotional.

In Study 2, overall, the individuals were adopted fairly quickly ( $\approx 59$ days), but the average Length of Stay in a shelter can vary widely within and between geographical areas (e.g. other UK shelters have reported a mean of 27 days: Battersea, 2014; whereas Swedish shelters have reported more than 90 days: Eriksson et al., 2009). There was also a bias towards one sex, with males being adopted quicker even though it was the less abundant sex available. This sex preference has been reported before in other studies (Lepper et al., 2002; Fantuzzi et al., 2010). From all the behavioural variables examined, only rub was significantly correlated with the Length of Stay. This demonstrates that there was a clear relationship between the frequency of rub and the adopters' decision: cats that had higher frequencies of rubbing were adopted quicker.

$\mathrm{Rub}$ is a behaviour that has been examined previously in domestic and wild cats, even though it has not been fully established why cats rub themselves on conspecifics, people and objects. It has been proposed to be a greeting and friendly energy releasing behaviour (Moelk, 1979), a submissive behaviour (Bradshaw et al., 2012) or having facultative functions depending on the social partner or body part used to rub. Rubbing may also be context-dependent, for example, may serve to deposit or pick up a scent, as a visual display or social signal, as a pre-copulatory interaction and/or to strengthen social bonds (Reiger, 1979; Freeman, 1983; Mellen, 1993; van den Bos and de Cock Buning, 1994; Matoba et al., 2013). It is also possible that rubbing has all of these functions at different proximate and ultimate levels (Tinbergen, 1963). Some authors have noted a distinction between scent marking rub and social rub (Johnson, 1973; Peters and Mech, 1975; Feldman, 1994; Bel et al., 1995; Blumstein and Henderson, 1996; Weiss et al., 2015). However, given the experimental setup of this study, social rub (also called bunting or allorubbing) is a more appropriate contextualization of the behaviour, since it was focused on the human-cat interaction. In domestic cats, rubbing behaviour is directed more towards owners than strangers (Edwards et al., 2007) and so could be an adaptation to interact with humans to obtain investment (Shreve and Udell, 2015). Cats seem to prefer being stroked by humans in specific facial areas (temporal region) and since humans do not use face or body rub as part of their normal species social repertoire, stroking (i.e. hand rubbing) could be the functional equivalent of 
a)

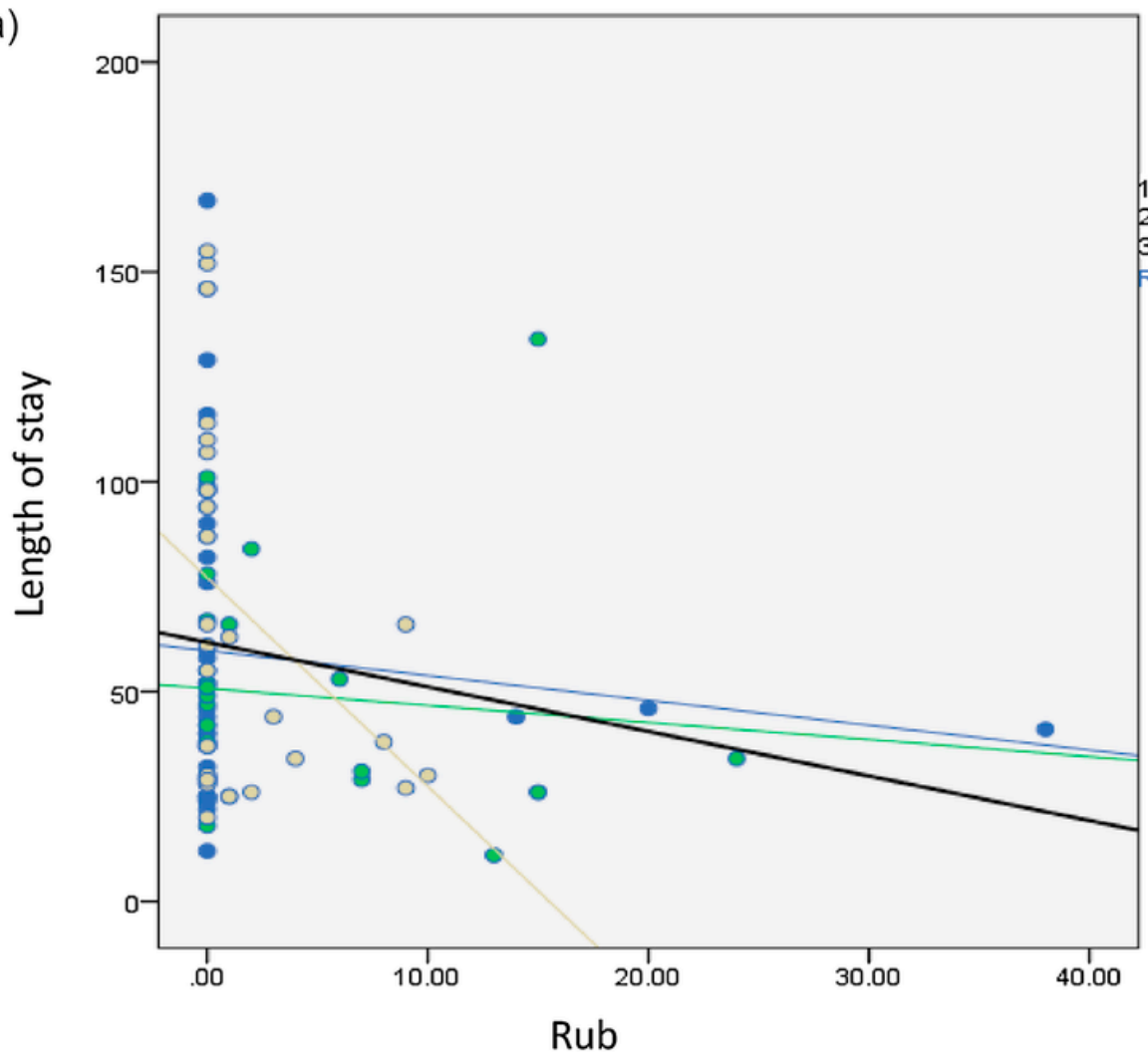

Group_sit

Q 1.00

2.00

3.00

.00: $R^{2}$ Linear $=0.017$

.00: $R^{2}$ Linear $=0.009$

3.00: $R^{2}$ Linear $=0.130$

$R^{2}$ Linear $=0.032$

b)

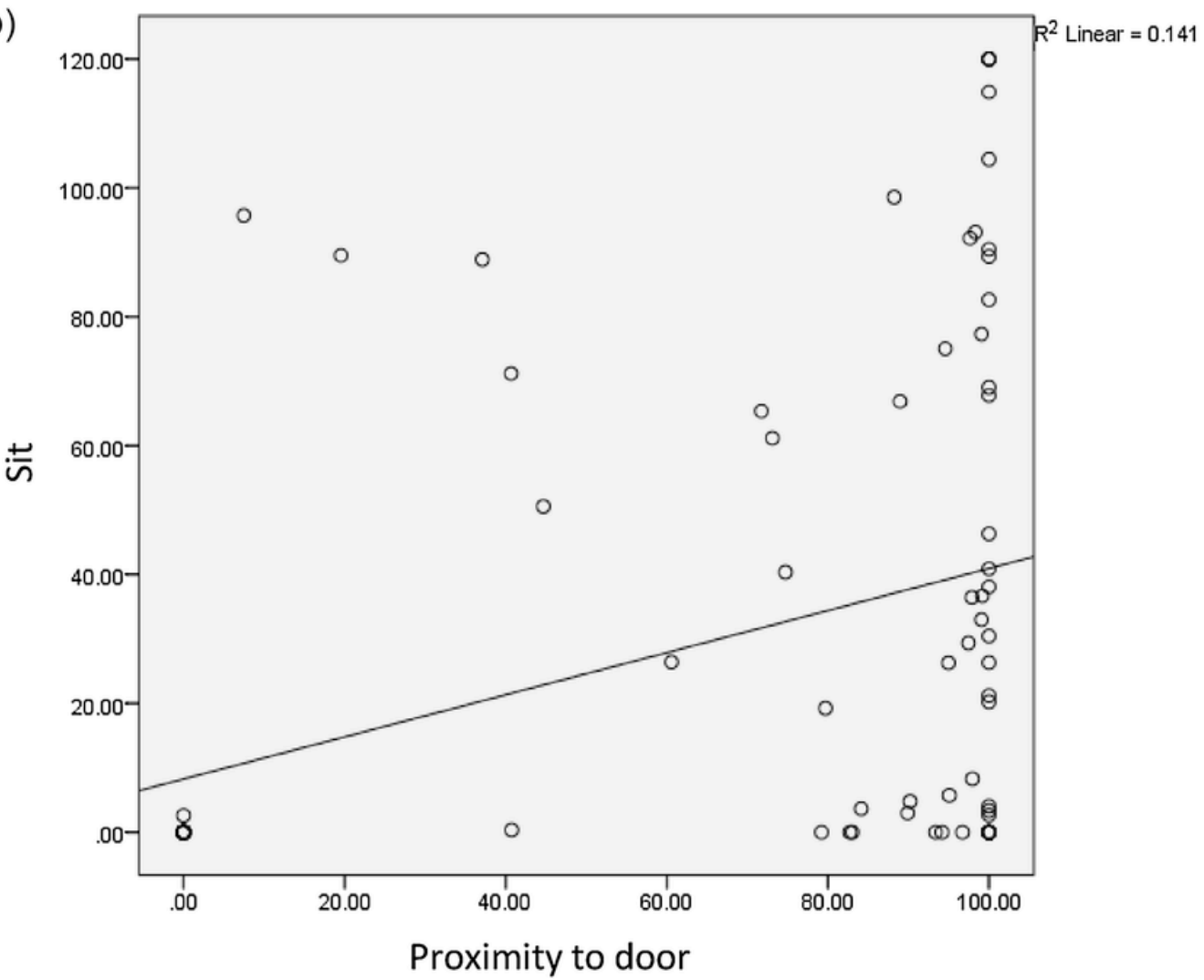




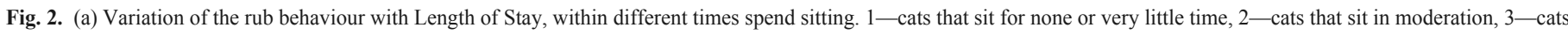
that sit for a long time. (b) Variation of sitting time and proximity to door (in percentage).

mutual body and face rubbing (Soennichsen and Chamove, 2002; Shreve and Udell, 2015). Rubbing was also clustered with the tail up signal, which is only shown in greeting and affiliative contexts (Cameron-Beaumont, 1997; Cafazzo and Natoli, 2009), and hind legs, paw the door, ears flattener (EAD103), rub, whiskers retractor (AU200) and body shake (AD160), which might suggest that all these behaviours have a similar affiliative communicative meaning. Therefore, human directed rubbing might have been selected for as a cat-human communication signal, as a pro-social affiliative indicator.

It might also be possible that cats that stay for a long period in the shelter might display less of the attractive behaviours (rub, tail up, etc.) as a result of a decrease in overall activity (Gouveia et al., 2011) and thus increase even further their Length of Stay. However, as in our study the maximum Length of Stay $(<13$ months) was much shorter than in Gouveia et al.'s study ( $>7$ years), this seems to not be the case in our study sample.

Even though we found a wide range of facial movements in the domestic cat through development of CatFACS, there was no indication that any particular facial expression was associated with faster selection by humans. In humans, facial expressions are at the core of communication and emotion expression (Ekman, 1999) and in the other most popular domestic animal, the dog, a high frequency of the facial movement to raise the inner brow showed an increase in speed of adoption from dog shelters (Waller et al., 2013). Adult dogs possess varied infantilized morphological features (e.g. proportionally shorter snout: Morey, 1994) and it is thought that the inner brow raiser acts to enhance the already very paedomorphic features of the dog. Thus, Waller et al. (2013) suggested that this particular facial expression explores, in some way, the sensory preferences of humans and consequently, drives the domestication process in this species. In cats, the neotenisation processes seem to be restricted to the vocalisations (Nicastro, 2004; Yeon et al., 2011) and do not seem to be present in facial expressions. Moreover, the current study was not able to identify any effect from facial expressions or vocalisations in human preferences when selecting a companion cat. When compared with dogs, cats have a shorter and less function-driven domestication history with humans (Vilà et al., 1997; Driscoll et al., 2009a). Cats' ancestors probably exploited the human environment and went through a self-domestication process, in which they were tolerated but not actively selected by humans (Driscoll et al., 2009b). Additionally, due to the different nature of the human-wolf and human-wildcat relationship, subsequent differences resulted in the modern domestic descendant species. Finally, the fact that dogs are social and cats are facultatively social (Bradshaw and Cameron-Beaumont, 2000), might also contribute towards the absence of specific communicative signals when interacting with humans. Some authors even argue that the domestic cat is not fully domesticated and is still undergoing evolutionary pressures (Driscoll et al., 2009a; Bradshaw, 2013).

\section{Conclusions}

The newly developed CatFACS tool is a valuable resource that can be applied to examine cat facial expression in a systematic, standardised and objective manner.

The results of this study suggest that cat behaviours such as facial expressions and vocalisations (usually crucial in communicative contexts in other animals) do not seem to affect humans' decisions when adopting a cat in a shelter context. This is in contrast to previously reported data on domestic dogs (Waller et al., 2013). Instead, rubbing was the only behaviour affecting the cats' adoption rate. Rubbing behaviour is present in the domestic cat ancestor, and so is likely a direct transfer from the cat-cat behavioural repertoire rather than the result of direct domestication pressures. Rubbing is also an overt pro-social behaviour, suggesting that humans are more responsive to overt indicators of friendliness in cats and suitability as a pet, rather than subtle perceptual biases. The findings shed light into the domestication processes that transformed the modern cat, but also contribute to our understanding of adoption processes in cat shelters.

\section{Conflicts of interest}

The authors declare that there are no conflicts of interest.

\section{Uncited reference}

\section{Acknowledgements}

This work was supported by a Feline Friends Research Donation to BW. The funder had no involvement in any part of this study. Further thanks to: Godstone and Southall RSPCA, and IWCP for data collection; Catarina Ferreira, Lauren Finka, Patrizia Piotti, Sarah Ellis and Will Higgs (skullsite.co.uk) for videos and photographs; Inês Martins for anatomical images; www.youtube.com users for permission to use their clips; Mateja Lasnik and Jennifer Wathan for reliability coding. Daniel Mills for promoting and commenting on the development of CatFACS. Please find further acknowledgements on www.CatFACS. com.

\section{Appendix A. Supplementary data}

Supplementary data associated with this article can be found, in the online version, at http://dx.doi.org/10.1016/j.applanim.2017.01.005.

\section{References}

Ahl, A.S., 1986. The role of vibrissae in behavior: a status review. Vet. Res. Commun. 10 (1), 245-268.

Archer, J., Monton, S., 2011. Preferences for infant facial features in pet dogs and cats. Ethology 117 (3), 217-226.

Barry, K.J., Crowell-Davis, S.L., 1999. Gender differences in the social behavior of the neutered indoor-only domestic cat. Appl. Anim. Behav. Sci. 64 (3), 193-211.

Bartko, J.J., 1976. On various intraclass correlation reliability coefficients. Psychol Bull. 83 (5), 762.

Battersea (2014). Available at https://www.battersea.org.uk/apex/ webpressrelease?nsid=13228\&pageId=pressrelease. (Accessed 1 May 2016).

Bel, M.C., Porteret, C., Coulon, J., 1995. Scent deposition by cheek rubbing in the alpine marmot (Marmota marmota) in the French Alps. Can. J. Zool. 73 (11), 2065-2071.

Belin, P., Fecteau, S., Charest, I., Nicastro, N., Hauser, M.D., Armony, J.L., 2008. Human cerebral response to animal affective vocalizations. Proc. R. Soc. Lond. B: Biol. Sci. 275 (1634), 473-481.

Blumstein, D.T., Henderson, S.J., 1996. Cheek-rubbing in golden marmots (Marmota caudata aurea). J. Zool. 238 (1), 113-123.

Bowden, R.E., Mahran, Z.Y., 1956. The functional significance of the pattern of innervation of the muscle quadratus labii superioris of the rabbit, cat and rat. J. Anat. 90 (Pt 2), 217.

Bradshaw, J., Cameron-Beaumont, C., 2000. The signalling repertoire of the domestic cat and its undomesticated relatives. In: Turner, D.C., Bateson, P. (Eds.), The Domestic Cat: the Biology of Its Behaviour. Cambridge University Press, Cambridge. 
Bradshaw, J.W., Casey, R.A., Brown, S.L., 2012. The Behaviour of the Domestic Cat. CABI.

Bradshaw, J., 2013. More than a feline. New Sci. 219 (2934), 44-47.

Bradshaw, J.W., 2016. Sociality in cats: a comparative review. J. Vet. Behav.: Clin. Appl. Res. 11, 113-124.

Brown

and

Mor-

gan,

2015 Brown W.P., Morgan K.T., Age, breed designation, coat color, and coat pattern influenced the length of stay of cats at a no-kill shelter, J. Appl. Anim. Welf. Sci. 18 (2) (2015) 169-180.

Budaev, S.V., 2010. Using principal components and factor analysis in animal behaviour research: caveats and guidelines. Ethology 116 (5), 472-480.

Burrows, A.M., 2008. The facial expression musculature in primates and its evolutionary significance. Bioessays 30 (3), 212-225.

Caeiro, C.C., Waller, B.M., Zimmermann, E., Burrows, A.M., Davila-Ross, M., 2013. OrangFACS: a muscle-based facial movement coding system for orangutans (Pongo spp.). Int. J. Primatol. 34 (1), 115-129.

Cafazzo, S., Natoli, E., 2009. The social function of tail up in the domestic cat (Felis silvestris catus). Behav. Process. 80 (1), 60-66.

Cameron-Beaumont, C., 1997. Visual and Tactile Communication in the Domestic Cat (Felis Silvestris Catus) and Undomesticated Small-felids, Doctoral Dissertation. University of Southampton.

Casey, R.A., Vandenbussche, S., Bradshaw, J.W., Roberts, M.A., 2009. Reasons for relinquishment and return of domestic cats (Felis silvestris catus) to rescue shelters in the UK. Anthrozoös 22 (4), 347-358.

UK Cat Behaviour Working Group, 1995. An Ethogram for Behavioural Studies of the Domestic Cat (Felis Silvestris Catus L.). Universities Federation for Animal Welfare (UFAW), England.

Cohn, J.F., Ambadar, Z., Ekman, P., 2007. Observer-based measurement of facial expression with the Facial Action Coding System. In: Coan, J.A., Allen, J.J.B. (Eds.), The Handbook of Emotion Elicitation and Assessment. Oxford University Press, Oxford, pp. 203-221.

Crouch, J.E.J.E., 1969. Text-Atlas of Cat Anatomy. Lea \& Febiger, Philadelphia, Chicago.

Cumming, J.A., Wooff, D.A., 2007. Dimension reduction via principal variables. Comput. Stat. Data Anal. 52 (1), 550-565.

Curtis, T.M., Knowles, R.J., Crowell-Davis, S.L., 2003. Influence of familiarity and relatedness on proximity and allogrooming in domestic cats (Felis catus). Am. J. Vet. Res. 64 (9), 1151-1154.

Dards, J.L., 1983. The behaviour of dockyard cats: interactions of adult males. Appl. Anim. Ethol. 10 (1-2), 133-153.

Darwin, C., 1872. The Expression of Emotions in Animals and Man. Murray, London.

Davison, A., 1927. Mammalian Anatomy: With Special Reference to the Cat. P. Blakiston's Son \& Company, Philadelphia.

Delgado, M.M., Munera, J.D., Reevy, G.M., 2012. Human perceptions of coat color as an indicator of domestic cat personality. Anthrozoös 25 (4), 427-440.

Diogo, R., Wood, B.A., Aziz, M.A., Burrows, A., 2009. On the origin, homologies and evolution of primate facial muscles, with a particular focus on hominoids and a suggested unifying nomenclature for the facial muscles of the Mammalia. J. Anat. 215 (3), 300-319.

Diogo, R., Pastor, F., De Paz, F., Potau, J.M., Bello-Hellegouarch, G., Ferrero, E.M., Fisher, R.E., 2012. The head and neck muscles of the serval and tiger: homologies, evolution, and proposal of a mammalian and a veterinary muscle ontology. Anat. Rec. 295 (12), 2157-2178.

Done, S.H., Goody, P.C., Evans, S.A., Stickland, N.C., 1996. Color atlas of veterinary anatomy. The Dog and Cat. vol. 3. Mosby, London.

Driscoll, C.A., Menotti-Raymond, M., Roca, A.L., Hupe, K., Johnson, W.E., Geffen, E., Harley, E.H., Delibes, M., Pontier, D., Kitchener, A.C., Yamaguchi, N., 2007. The Near Eastern origin of cat domestication. Science 317 (5837), 519-523.

Driscoll, C.A., Macdonald, D.W., O'Brien, S.J., 2009. From wild animals to domestic pets, an evolutionary view of domestication. Proc. Natl. Acad. Sci. U. S. A. 106 (Suppl. 1), 9971-9978.

Driscoll, C.A., Clutton-Brock, J., Kitchener, A.C., O'Brien, S.J., 2009. The taming of the cat. Sci. Am. 300 (6), 68-75.

Edwards, C., Heiblum, M., Tejeda, A., Galindo, F., 2007. Experimental evaluation of attachment behaviors in owned cats. J. Vet. Behav.: Clin. Appl. Res. 2 (4), $119-125$.

Ekman, P., Friesen, W.V., 1976. Measuring facial movement. Environ. Psychol. Nonverbal Behav. 1 (1), 56-75.

Ekman, P., Friesen, W.V., 1978. Facial Action Coding System. Consulting Psychologists Press, Palo Alto, CA.

Ekman, P., Friesen, W.V., Hager, J.C. (2002). The Facial Action Coding System Manual (FACS).
Ek-

man,

1999. P. Ekman, Facial expressions, in: T. Dalgleish, M.J. Power (Eds.), Handbook of Cognition and Emotion, John Wiley \& Sons, Ltd, Chichester, UK, 1999, pp. 301-320.

Eriksson, P., Loberg, J., Andersson, M., 2009. A survey of cat shelters in Sweden. Anim. Welf. 18 (3), 283-288.

Euromonitor, 2015. Available at www.euromonitor.com/pet-care. (Accessed November 2015).

Fantuzzi, J.M., Miller, K.A., Weiss, E., 2010. Factors relevant to adoption of cats in an animal shelter. J. Appl. Anim. Welf. Sci. 13 (2), 174-179.

Faure, E., Kitchener, A.C., 2009. An archaeological and historical review of the relationships between felids and people. Anthrozoös 22 (3), 221-238.

Feldman, H.N., 1994. Methods of scent marking in the domestic cat. Can. J. Zool. 72 (6), 1093-1099.

Fitzgerald, B.M., Turner, D.C., 2000. Hunting behaviour of domestic cats and their impact on prey populations. In: Turner, D.C., Bateson, P. (Eds.), The Domestic Cat: the Biology of Its Behaviour. Cambridge University Press, Cambridge, pp. $151-176$.

Freeman, H., 1983. Behavior in adult pairs of captive snow leopards (Panthera uncia) Zoo Biol. 2 (1), 1-22.

Gaynor, J.S., Muir III, W.W., 2008. Handbook of Veterinary Pain Management. Mosby, Missouri.

Gourkow, N., Fraser, D., 2006. The effect of housing and handling practices on the welfare: behaviour and selection of domestic cats (Felis sylvestris catus) by adopters in an animal shelter. Anim. Welf. 15, 371-377.

Gourkow, N., 2001. Factors Affecting the Welfare and Adoption Rate of Cats in an Animal Shelter, Doctoral Dissertation. University of British Columbia.

Gouveia, K., Magalhães, A., de Sousa, L., 2011. The behaviour of domestic cats in a shelter: residence time, density and sex ratio. Appl. Anim. Behav. Sci. 130 (1), 53-59.

Gruart, A., Blzquez, P., Delgado-García, J.M., 1995. Kinematics of spontaneous, reflex, and conditioned eyelid movements in the alert cat. J. Neurophysiol. 74 (1), 226-248.

HSUS, 1995. The Humane Society of the United States, Available at http://www.humanesociety.org/ (Accessed November 2015).

Holden, E., Calvo, G., Collins, M., Bell, A., Reid, J., Scott, E.M., Nolan, A.M., 2014 Evaluation of facial expression in acute pain in cats. J. Small Anim. Pract. 55 (12), 615-621.

Hu, Y., Hu, S., Wang, W., Wu, X., Marshall, F.B., Chen, X., Hou, L., Wang, C., 2014. Earliest evidence for commensal processes of cat domestication. Proc. Natl. Acad. Sci. U. S. A. $111(1), 116-120$.

Huber, E., 1930. Evolution of facial musculature and cutaneous field of trigeminus. Part I. Q. Rev. Biol. 5 (2), 133-188.

Johnson, R.P., 1973. Scent marking in mammals. Anim. Behav. 21 (3), 521-535.

Kidd, A.H., Kidd, R.M., George, C.C., 1992. Successful and unsuccessful pet adoptions. Psychol. Rep. 70 (2), 547-561.

Kiddie, J., 2009. Intercat aggression within the household. Vet. Nurs. J. 24 (5), 51-52.

Lepper, M., Kass, P.H., Hart, L.A., 2002. Prediction of adoption versus euthanasia among dogs and cats in a California animal shelter. J. Appl. Anim. Welf. Sci. 5 (1), 29-42.

Leyhausen, P., Tonkin, B.A., 1979. Cat Behaviour. The Predatory and Social Behaviour of Domestic and Wild Cats. Garland STPM Press, New York.

Macdonald, D.W., Yamaguchi, N., Kerby, G., 2000. Group-living in the domestic cat: its sociobiology and epidemiology. In: Turner, D.C., Bateson, P. (Eds.), The Domestic Cat: the Biology of Its Behaviour. Cambridge University Press, Cambridge, pp. 95-118.

Matoba, T., Kutsukake, N., Hasegawa, T., 2013. Head rubbing and licking reinforce social bonds in a group of captive African lions, Panthera leo. PLoS One 8 (9), e73044.

McComb, K., Taylor, A.M., Wilson, C., Charlton, B.D., 2009. The cry embedded within the purr. Curr. Biol. 19 (13), 507-508.

Mellen, J.D., 1993. A comparative analysis of scent-marking, social and reproductive behavior in 20 species of small cats (Felis). Am. Zool. 33 (2), 151-166.

Merola, I., Mills, D.S., 2016. Behavioural signs of pain in cats: an expert consensus. PLoS One 11 (2), e0150040.

Mertens, C., Turner, D.C., 1988. Experimental analysis of human-cat interactions during first encounters. Anthrozoös 2 (2), 83-97.

Mills, M.G., Nel, J.A., Bothma, J.D.P., 1984. Notes on some smaller carnivores from the Kalahari Gemsbok National Park. Koedoe 27 (2), 221-227.

Mivart, G., 1881. The Cat, an Introduction to the Study of Backboned Animals, Especially Mammals. John Murray, London.

Moelk, M., 1944. Vocalizing in the house-cat; a phonetic and functional study. Am. J. Psychol. 57 (2), 184-205.

Moelk, M., 1979. The development of friendly approach behavior in the cat: a study of kitten-mother relations and the cognitive development of the kitten from birth to eight weeks. Adv. Study Behav. 10, 163-224. 
Montague, M.J., Li, G., Gandolfi, B., Khan, R., Aken, B.L., Searle, S.M., Minx, P., Hillier, L.W., Koboldt, D.C., Davis, B.W., Driscoll, C.A., 2014. Comparative analysis of the domestic cat genome reveals genetic signatures underlying feline biology and domestication. Proc. Natl. Acad. Sci. U. S. A. 111 (48), 17230-17235.

Morey, D.F., 1994. The early evolution of the domestic dog. Am. Sci. 82 (4), 336-347.

Muchlinski, M.N., Durham, E.L., Smith, T.D., Burrows, A.M., 2013. Comparative histomorphology of intrinsic vibrissa musculature among primates: implications for the evolution of sensory ecology and face touch. Am. J. Phys. Anthropol. 150 (2), 301-312.

Neidhart, L., Boyd, R., 2002. Companion animal adoption study. J. Appl. Anim. Welf. Sci. 5 (3), 175-192.

Nicastro, N., Owren, M.J., 2003. Classification of domestic cat (Felis catus) vocalizations by naive and experienced human listeners. J. Comp. Psychol. 117 (1), 44.

Nicastro, N., 2002. Acoustic correlates of human responses to domestic cat (Felis catus) vocalizations. J. Acoust. Soc. Am. 111 (5), 2393.

Nicastro, N., 2004. Perceptual and acoustic evidence for species-level differences in Meow vocalizations by domestic cats (Felis catus) and african wild cats (Felis silvestris lybica). J. Comp. Psychol. 118 (3), 287.

O'Connor, B.P., (2000). SPSS and SAS programs for determining the number of com ponents using parallel analysis and Velicer's MAP test. Behavior Research Methods, Instruments, \& Computers, 32(3), 396-402

Peters, R.P., Mech, L.D., 1975. Scent-marking in wolves: radio-tracking of wolf packs has provided definite evidence that olfactory sign is used for territory maintenance and may serve for other forms of communication within the pack as well. Am. Sci. 63 (6), 628-637.

Peters, G., Wozencraft, W.C., 1989. Acoustic communication by fissiped carnivores In: Gittleman, J.L. (Ed.), Carnivore Behavior, Ecology, and Evolution. Springer, US, pp. 14-56.

Podberscek, A.L., Blackshaw, J.K., 1988. Reasons for liking and choosing a cat as a pet. Aust. Vet. J. 65 (10), 332-333.

Price, E.O., 1984. Behavioral aspects of animal domestication. Q. Rev. Biol. 1-32.

Reiger, I., 1979. Scent rubbing in carnivores. Carnivores 2, 17-25.

Reighard, J.E., Jennings, H.S., 1901. Anatomy of the Cat. H. Holt, New York.

Salman, M.D., New Jr., J.G., Scarlett, J.M., Kass, P.H., Ruch-Gallie, R., Hetts, S., 1998. Human and animal factors related to relinquishment of dogs and cats in 12 selected animal shelters in the United States. J. Appl. Anim. Welf. Sci. 1 (3), 207-226.

Schwartz, J.H., Tattersall, I., 2000. The human chin revisited: what is it and who has it?. J. Hum. Evol. 38 (3), 367-409.

Serpell, J.A., 2000. Domestication and history of the cat. In: Turner, D.C., Bateson, P. (Eds.), The Domestic Cat: the Biology of Its Behaviour. Cambridge University Press, Cambridge, pp. 179-192.

Sharkin, B.S., Ruff, L.A., 2011. Broken bonds: understanding the experience of pet relinquishment. In: Blazina, C., Boyra, G., Shen-Miller, D.S. (Eds.), The Psychology of the Human-Animal Bond. Springer, New York, pp. 275-287.

Shreve, K.R.V., Udell, M.A., 2015. What's inside your cat's head? A review of cat (Felis silvestris catus) cognition research past, present and future. Anim. Cogn. 18 (6), 1195-1206.

Siegford, J.M., Walshaw, S.O., Brunner, P., Zanella, A.J., 2003. Validation of a temperament test for domestic cats. Anthrozoös 16 (4), 332-351
Soennichsen, S., Chamove, A.S., 2002. Responses of cats to petting by humans. Anthrozoös 15 (3), 258-265.

Tabor, R.K., 1997. Understanding Cats: Their History, Nature, and Behavior. Readers Digest, Pleasantville, New York.

Tinbergen, N., 1963. On aims and methods of ethology. Z. Tierpsychol. 20 (4), $410-433$.

Tomo, S., Tomo, I., Nakajima, K., Townsend, G.C., Hirata, K., 2002. Comparative anatomy of the buccinator muscle in cat (Felis domestica). Anat. Rec. 267 (1), 78-86.

Vick, S.J., Waller, B.M., Parr, L.A., Pasqualini, M.C.S., Bard, K.A., 2007. A cross-species comparison of facial morphology and movement in humans and chimpanzees using the facial action coding system (FACS). J. Nonverbal Behav. 31 (1), 1-20.

Vilà, C., Savolainen, P., Maldonado, J.E., Amorim, I.R., Rice, J.E., Honeycutt, R.L., Crandall, K.A., Lundeberg, J., Wayne, R.K., 1997. Multiple and ancient origins of the domestic dog. Science 276 (5319), 1687-1689.

Waller, B.M., Lembeck, M., Kuchenbuch, P., Burrows, A.M., Liebal, K., 2012. GibbonFACS: a muscle-based facial movement coding system for hylobatids. Int. J. Primatol. 33 (4), 809-821.

Waller, B.M., Peirce, K., Caeiro, C.C., Scheider, L., Burrows, A.M., McCune, S., Kaminski, J., 2013. Paedomorphic facial expressions give dogs a selective advantage. PLoS One 8 (12), e82686.

Weiss, E., Miller, K., Mohan-Gibbons, H., Vela, C., 2012. Why did you choose this pet? Adopters and pet selection preferences in five animal shelters in the United States. Animals 2 (2), 144-159.

Weiss, E., Mohan-Gibbons, H., Zawistowski, S., 2015. Animal Behaviour for Shelter Veterinarians and Staff. John Wiley \& Sons, New York.

Wells, D., Hepper, P.G., 1992. The behaviour of dogs in a rescue shelter. Anim. Welf. 1 (3), 171-186

Wells, D.L., Hepper, P.G., 2001. The behavior of visitors towards dogs housed in an animal rescue shelter. Anthrozoös 14 (1), 12-18.

Wexler, D.A., 1972. Method for unitizing protocols of descriptions of emotional states Journal of Supplemental Abstracts Service, Catalogue of Selected Documents in Psychology. Am. Psychol. Assoc. 2, 116.

Williams, B., Onsman, A., Brown, T., 2010. Exploratory factor analysis: a five-step guide for novices. Australas. J. Paramed. 8 (3).

Wolfe, R.C., 2001. The Social Organization of the Free Ranging Domestic Cat (Felis Catus) PhD Dissertation. University of Georgia, Athens, Georgia.

Yamaguchi, N., Driscoll, C.A., Kitchener, A.C., Ward, J.M., Macdonald, D.W., 2004 Craniological differentiation between European wildcats (Felis silvestris silvestris), African wildcats (F. s. lybica) and Asian wildcats (F. s. ornata): implications for their evolution and conservation. Biol. J. Linn. Soc. 83 (1), 47-63.

Yeon, S.C., Kim, Y.K., Park, S.J., Lee, S.S., Lee, S.Y., Suh, E.H., Houpt, K.A., Chang, H.H., Lee, H.C., Yang, B.G., Lee, H.J., 2011. Differences between vocalization evoked by social stimuli in feral cats and house cats. Behav. Process. 87 (2), $183-189$.

van den Bos, R., de Cock Buning, T., 1994. Social and non-social behaviour of domestic cats (Felis catus L.): a review of the literature and experimental findings. In: In: Proceedings of the Fifth FELASA Symposium on Welfare and Science. Royal Society of Medicine Press Ltd., London. pp. 53-57. 